\title{
Effective Removal of Algae from Water by Diatomite Enhanced Graphene Oxide Flocculation
}

\author{
Lili Dong', ${ }^{1,}$ Mingxin Huo ${ }^{1,2 *}$ \\ ${ }^{1}$ Key Laboratory of Songliao Aquatic Environment, Ministry of Education, Jilin Jianzhu University, \\ Changchun 130118, China \\ ${ }^{2}$ School of Environment, Northeast Normal University, Changchun 130117, China
}

Received: 22 June 2020

Accepted: 25 December 2020

\begin{abstract}
The ability of graphene oxide (GO) to function as a flocculant capable of mediating the removal of algae and associated extracellular organic matter (EOM) from water was assessed. GO was demonstrated to mediate the dose-dependent removal of algae via flocculation, with $40 \mathrm{mg} / \mathrm{L}$ GO being sufficient to remove $100 \%$ of chlorophyll-a $\left(\right.$ chl-a) and $99.1 \%$ of the $\mathrm{UV}_{254}$. Diatomite addition failed to enhance GO flocculation efficiency or to reduce the necessary GO dosage, although it did result in a significantly reduced settling time, with denser floc and a corresponding increase in supernatant ratio. GO-mediated algae flocculation was primarily achieved via netting and bridging mechanisms, with diatomite addition leading to the conversion of a subset of two-dimensional GO nets into threedimensional nets containing a diatomite core. Flocculation efficiency was comparable under acidic and neutral conditions but declined significantly with rising $\mathrm{pH}$ when $\mathrm{pH} \geq 7$, with just $13.8 \%$ of chl-a being removed at $\mathrm{pH}$ of 10 . At $\mathrm{pH}$ of 5 , more than $60 \%$ of EOM and $57.6 \%$ to $90.1 \%$ of the disinfection byproduct formation potentials were reduced following the $\mathrm{GO} /$ diatomite flocculation process, and following flocculation the solution always had a final $\mathrm{pH}$ of $7.4 \pm 0.4$ regardless of the starting $\mathrm{pH}$.
\end{abstract}

Keywords: algae, graphene oxide, flocculation, diatomite, extracellular organic matter

\section{Introduction}

Climate change and related anthropogenic activities have led to the development of increasingly severe algal blooms [1-5]. These blooms can have both direct and metabolite-mediated indirect adverse impacts on water quality, resulting in its discoloration, poor taste or

*e-mail: huomx097@outlook.com

odor, and contamination with algal toxins [5, 6-9]. Such blooms also negatively affect the efficiency of water treatment processes [10-12], with algal removal early during the treatment process being essential in order to minimize this impact. Potassium permanganate [13], potassium ferrate (VI) [14], chlorine [15], ozone [16] and advance oxidation process [17] have all been employed as pre-oxidants that can facilitate the enhanced removal of algae from drinking water, but these compounds can damage algal cell membranes and result in the release of algae-derived organic matter into the water supply 
[18]. As such, there is a clear value in developing an algae control strategy capable of removing algae from solution without damaging their cellular structure.

Flocculation strategies can allow for the simple and efficient separation of water and solid or colloidal particles. The most commonly utilized flocculants include polyacrylamide and alum- and iron-based inorganic flocculants. Such compounds, however, are not compatible with a large-scale water purification approach as they would lead to the accumulation of noxious monomers or metal ions that have the potential to adversely impact human health and the environment [19]. The identification of an environmentally friendly flocculant that can purify water in a cost-effective manner is therefore essential.

Owing to their unique physicochemical properties, graphene-based materials have been the focus of substantial research interest in recent years [20]. Highly oxidized graphene oxide (GO) contains a range of oxygen-based hydroxyl, carboxyl, carbonyl, and epoxy functional groups on its surface [21], making it ideally suited to adsorbing organic pollutants and heavy metals [22]. Importantly, GO is easy to synthesize in a cost-effective and large-scale manner, and it is more biocompatible than are alternative graphene-based materials [23]. Yang et al. [24] first explore the potential use of $\mathrm{GO}$ as a flocculant capable of removing kaolin, hematite, humic acid, and cationic light yellow 7GL from water under a range of conditions. In this context, the authors determined that GO was capable of mediating solution decontamination via sweeping and charge neutralization effects. Other researchers have shown GO to be well-suited to reducing water turbidity and removing biological contaminants from solution, making it an ideal alum alternative for water treatment efforts [25]. Despite its promising flocculation efficiency, up to 1 hour following treatment is necessary for the settling of GOmediated flocs to occur owing to their low density. Approaches that can aid in this process by reducing this setting time will therefore improve the utility of GO as a flocculant.

Diatomite is a highly porous compound with excellent chemical stability and hydrophilicity [26], and it has received approval as a food-grade material from the US Food and Drug Administration [27]. Previous studies have explored the successful use of diatomite for the safe and effective treatment of water and wastewater supplies owing as its ability to function as an adsorbent or a flocculant [28-31]. Given its high porosity and the fact that it is denser than water, diatomite has the potential to be ideally suited to serving as a GO flocculant aid. However, to date, there have not been sufficient studies assessing the ability of diatomite to enhance GO-mediated flocculation of algae during the process of water treatment. To that end, the present study was designed to explore the utility of diatomite as a means of improving GO-mediated algae removal via flocculation.

\section{Experimental}

\author{
Materials and Methods
}

\section{Graphene Oxide Preparation and Characterization}

A pressurize oxidation method was used to prepare $\mathrm{GO}$, as previously outlined by Bao et al. [32]. Briefly, graphite $(5.0 \mathrm{~g}), \mathrm{KMnO}_{4}(25.0 \mathrm{~g})$, and concentrated sulphuric acid $(250 \mathrm{~mL})$ were mixed within a teflon reactor prior to being placed in a stainless steel autoclave that was heated to $100^{\circ} \mathrm{C}$ for $1.5 \mathrm{~h}$. The resultant sample was then diluted in a $500 \mathrm{~mL}$ volume of deionized water, to which $30 \% \mathrm{H}_{2} \mathrm{O}_{2}$ was gradually added until the slurry changed to a golden yellow color. At this point, $\mathrm{HCl}$ and deionized water were used to wash the sample until a $\mathrm{pH}$ of 7 was achieved, yielding humid GO that was then dried at $100^{\circ} \mathrm{C}$. Once dried, GO was characterized and a $2 \mathrm{mg} / \mathrm{mL}$ GO stock solution was prepared using Milli-Q water.

Both SEM and FTIR were used to characterize GO preparations, with an SEI Model XL30-ESEM TEM being used to assess GO surface morphology, and a Nicolet 6700 FTIR spectrometer being used to record FTIR spectra across a $500-4000 \mathrm{~cm}^{-1}$ scanning wave range.

\section{Algae and Extracellular Organic Matter (EOM) Suspension Preparation}

For this study, Microcystis aeruginosa was used as a model algae as it is a dominant cyanobacteria in many eutrophic bodies of water in China [33]. Algae were obtained from the Wuhan Institute of Hydrobiology of Chinese Academy of Sciences, and were grown using BG11 media in a $25^{\circ} \mathrm{C}$ incubator. Algae were harvested during the stationary phase of growth and were spun for 10 minutes at 10,000 rpm, after which $0.7 \mu \mathrm{m}$ cellulose acetate membranes were used to filter supernatants, with the organic compounds in this filtrate serving as EOM for the purposes of this study. Cells that were isolated via centrifugation were washed thrice prior to use, and chlorophyll-a (chl-a) concentrations in these prepared algae were measured.

\section{Jar-Test Experiments}

Prior to flocculation tests, algal suspensions were prepared by adding tap water containing algae at a concentration of $500 \mu \mathrm{g} / \mathrm{L}$ chl-a. $\mathrm{HCl}$ or $\mathrm{NaOH}$ solutions $(0.1 \mathrm{~mol} / \mathrm{L})$ were used to adjust the $\mathrm{pH}$ of this solution as appropriate. For jar tests, $250 \mathrm{~mL}$ jars and a six-place programmed paddle mixer (Model TA6, Wuhan Hengling Technology Co., Ltd.) were utilized at room temperature. A known GO stock solution was combined with algae-spiked water samples, after which flocculation was performed via 2 minutes of rapid mixing (350 rpm), 15 minutes of slow mixing $(50 \mathrm{rpm})$, and a $30 \mathrm{~min}$ settling phase. For diatomite 
experiments, $200 \mathrm{mg} / \mathrm{L}$ of diatomite was added prior to $\mathrm{GO}$ addition.

\section{Analytical Methods}

Following the settling phase, supernatant samples were collected and used for analyses of $\mathrm{pH}$, chl-a, DOC, and $\mathrm{UV}_{254}$. A827 pH meter (Metrohm, Switzerland) was used for $\mathrm{pH}$ analyses, while a TOC-L CPH (Shimadzu, Japan) was used for DOC analyses, and a T6 spectrophotometer (Persee, China) was used to assess $\mathrm{UV}_{254^{\circ}}$. For chl-a measurements, samples were passed through a $0.45 \mu \mathrm{m}$ filter after which $10 \mathrm{~mL}$ of absolute ethanol was used for chlorophyll extraction. Optical density (OD) was then measured at 630, 647, 664, and $750 \mathrm{~nm}$ with a T6 spectrophotometer, and the following equation was used to calculate $c h l-a$ concentration:

$C(\mu g / L)=\frac{\left(11.64 \times\left(D_{664}-D_{750}\right)-2.16 \times\left(D_{647}-D_{750}\right)+0.10 \times\left(D_{630}-D_{750}\right)\right) \times 10}{V}$

With $\mathrm{C}$ representing the concentration of $c h l-a, \mathrm{D}_{630}$, $\mathrm{D}_{647}, \mathrm{D}_{664}$, and $\mathrm{D}_{750}$ representing the OD at 630, 647, 664 and $750 \mathrm{~nm}$, respectively, and $\mathrm{V}(\mathrm{L})$ representing the sample volume.

The DBPFPs of the samples the GO/diatomite flocculation process were analysed. Samples were adjusted to $\mathrm{pH} 7.0 \pm 0.2$ with $0.1 \mathrm{M} \mathrm{HCl}$ or $\mathrm{NaOH}$. Then, approximately $45 \mathrm{mg} / \mathrm{L} \mathrm{NaOCl}$ was added and the resulting solutions were incubated in dark at $20^{\circ} \mathrm{C}$ for $24 \mathrm{~h}$. Sodium thiosulfate was used to neutralize residual chlorine. THMs, haloacetonitriles (HANs) and chloral hydrate $(\mathrm{CH})$ were measured cording to our previous work [34]. Haloacetic Acids were measured with EPA Method 552.3 by gas chromatograph with an electron capture detector (Clarus 680, PerkinElmer, USA).

\section{Results and Discussion}

\section{GO Characterization}

SEM images revealed the GO preparations in this study to exhibit a partially transparent reticulate structure with some surface folding (Fig. 1). An XPS analysis demonstrated this GO to be primarily composed of carbon and oxygen, with a $\mathrm{C} / \mathrm{O}$ atomic ratio of $62 \% / 38 \%$, slightly higher than that reported previously $[32,35]$. In the FTIR spectra, $\mathrm{C}-\mathrm{OH}$, epoxy $\mathrm{C}-\mathrm{O}, \mathrm{C}=\mathrm{C}$, and $\mathrm{C}=\mathrm{O}$ groups were evident (Fig. 2), confirming the introduction of many oxygen-containing groups into GO [27, 36-37].

\section{The Impact of GO Concentration on Algae Removal}

The removal of algae from water across a range of $\mathrm{GO}$ doses $(0-60 \mathrm{mg} / \mathrm{L})$ was investigated. As can

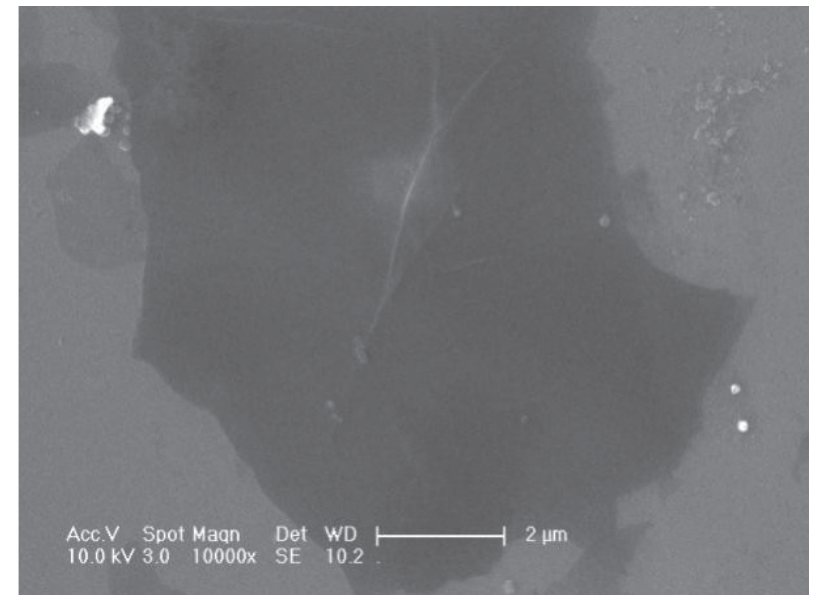

Fig. 1. SEM image of GO.

be seen from Fig. 3, the GO flocculation was able to successfully remove algae from solution, with chl-a and $\mathrm{UV}_{254}$ removal efficiencies from $<3 \%$ to $100 \%$ and $99.1 \%$, with GO concentrations increased from 0 to $40 \mathrm{mg} / \mathrm{L}$. No additional efficiency was achieved at doses $>40 \mathrm{mg} / \mathrm{L}$, although floc density did increase further, with supernatant ratios following a 30 min settling period of $45 \%, 65 \%$, and $71 \%$ at GO concentration of 10,40 , and $60 \mathrm{mg} / \mathrm{L}$, respectively.

Despite its excellent flocculation efficiency in this context, the resultant floc was of fairly low density such that even slight agitation resulted in its resuspension. The use of a flocculant aid is thus necessary to improve the utility of GO as a flocculant.

\section{The Impact of Diatomite on Flocculation}

We found that despite its porous structure and ability to adsorb certain pollutants, diatomite was not able to directly mediate algae removal (Fig. 4), consistent with previous findings [38]. $\mathrm{GO}$ and $\mathrm{GO} /$ diatomite treatments

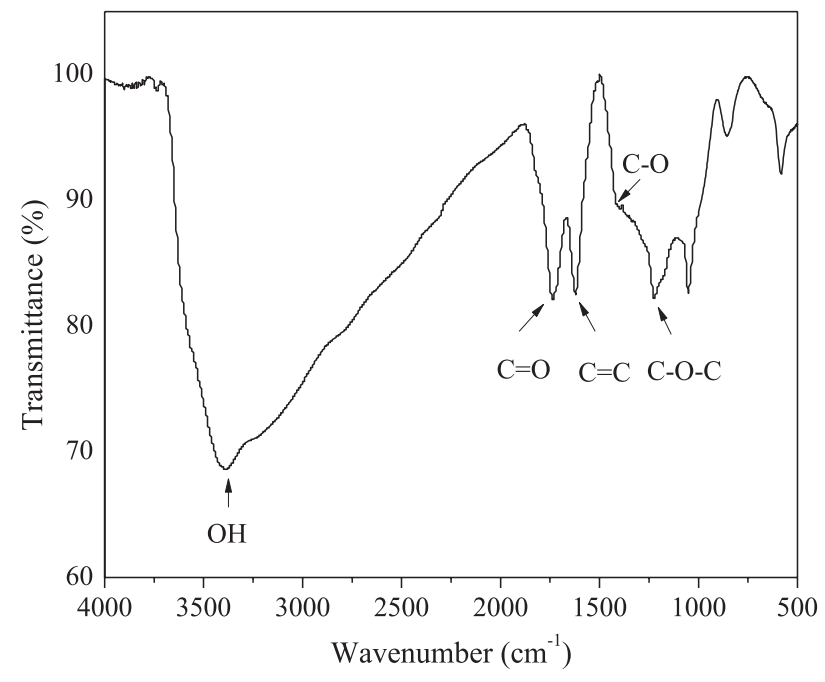

Fig. 2. FTIR spectra of GO. 


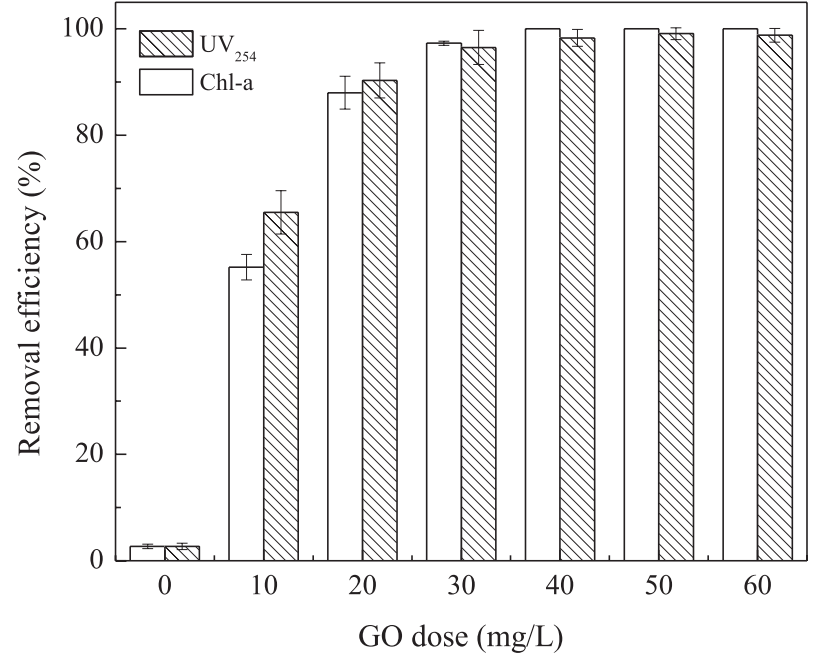

Fig. 3. Effect of GO concentration on algae removal (algae concentration: $2-5 \times 10^{6}$ cell $/ \mathrm{mL}$ ).

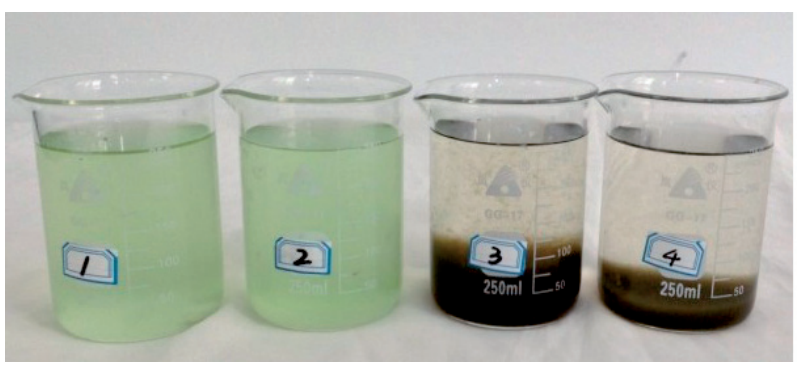

Fig. 4. Effect of different treatments on algae removal.

Table 1. Comparison of the algae removal efficiency by GO and $\mathrm{GO} /$ diatomite flocculation.

\begin{tabular}{|c|c|c|c|}
\hline $\begin{array}{c}\text { Concentration } \\
\text { of } C h l-a\end{array}$ & $\begin{array}{c}\text { Concentration } \\
\text { of GO }\end{array}$ & $\begin{array}{c}\text { Removal } \\
\text { efficiency by } \\
\text { GO }\end{array}$ & $\begin{array}{c}\text { Removal } \\
\text { efficiency by } \\
\text { GO/diatomite }\end{array}$ \\
\hline$(\mu \mathrm{g} / \mathrm{L})$ & $(\mathrm{mg} / \mathrm{L})$ & $(\%)$ & $(\%)$ \\
\hline 52 & 40 & 100 & 100 \\
\hline 130 & 40 & 100 & 100 \\
\hline 260 & 40 & 100 & 100 \\
\hline 520 & 40 & 100 & 100 \\
\hline 1040 & 40 & 100 & 100 \\
\hline 1300 & 40 & $96.4 \pm 3.7$ & $95.6 \pm 2.2$ \\
\hline 2600 & 40 & $47.2 \pm 5.1$ & $49.1 \pm 4.0$ \\
\hline 2600 & 60 & $75.1 \pm 6.7$ & $73.7 \pm 3.5$ \\
\hline 2600 & 80 & $94.3 \pm 1.9$ & $96.1 \pm 4.2$ \\
\hline 2600 & 100 & 100 & 100 \\
\hline
\end{tabular}

Diatomite: $200 \mathrm{mg} / \mathrm{L}$

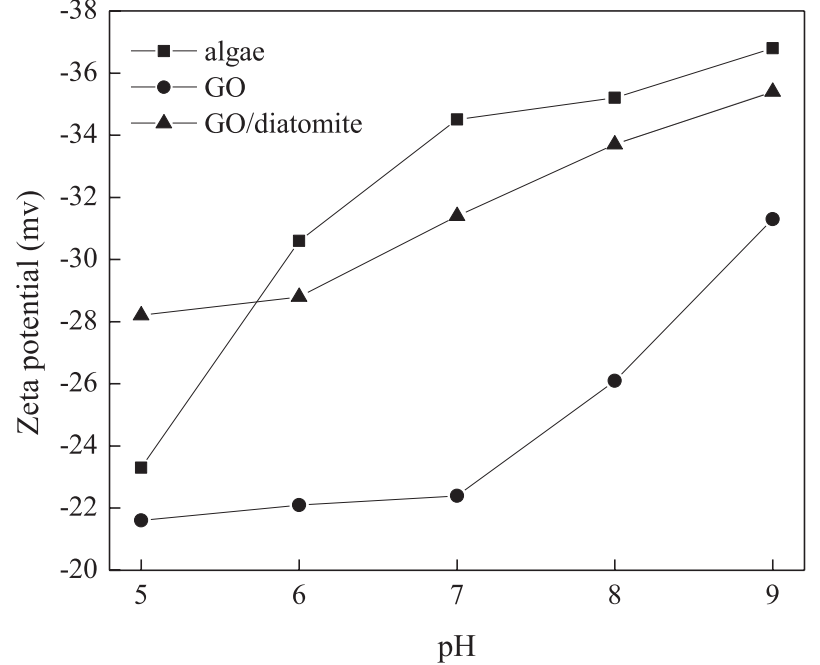

Fig. 5. Zeta potential-pH profiles of algae, GO, and $\mathrm{GO} /$ diatomite.

were both able to efficiently remove algae from solution via flocculation (Table 1). While the floc generated by the addition of GO alone was of low density, achieving a supernatant ratio of just $65 \%$ after a 30 min settling period, the addition of diatomite significantly improved this such that after 30 minutes a $90 \%$ supernatant ratio was achieved. Importantly, this $90 \%$ ratio was achieved after just 8 minutes, in which time GO treatment achieved a mere $35 \%$ value. In addition, supernatant turbidity values following a $30 \mathrm{~min}$ settling period in GO- and GO/diatomite-treated samples were 4.3 and 1.2 NTU, respectively.

The efficiency of algae removal by $\mathrm{GO}$ and $\mathrm{GO} /$ diatomite across a range of different algae concentrations is compiled in Table 1. There were no clear differences in removal efficiency values when comparing GO and $\mathrm{GO} /$ diatomite-treated samples, indicating that diatomite addition does not improve GO flocculation efficiency or allow for reductions in the effective GO dosage. Even so, the above results clearly demonstrate the ability of diatomite to increase floc density, thereby reducing settling times and increasing supernatant ratio values.

\section{The Mechanistic Basis for GO-Mediated Flocculation}

Yang et al. [24] utilized GO to mediate the flocculation and removal of contaminants with a range of surface charge values from water, revealing that this was achieved primarily via charge neutralization and sweeping flocculation mechanisms. To determine the mechanistic basis for flocculation in the present $\mathrm{GO} /$ algal system, zeta potential values for algae, $\mathrm{GO}$, and GO/diatomite were measured (Fig. 5). This analysis revealed both algae and GO to have negative surface charges within tested experimental $\mathrm{pH}$ ranges, 
indicating that electrostatic neutralization is not a driver of GO and $M$. aeruginosa cell aggregation.

$\mathrm{GO}, \mathrm{GO} /$ algae, GO/diatomite, and $\mathrm{GO} /$ diatomite/ algae were assessed via SEM, revealing GO to be partially transparent with some surface folding and with a two-dimensional net- or bridge-like structure having captured the algal cells (Fig. 6). When diatomite was added these two-dimensional nets appeared to be partially converted into three-dimensional nets with a diatomite core, with $M$. aeruginosa cells similarly being captured by GO netting and bridging.

As GO contains many oxygen-containing groups, it can form strong hydrogen-bonding interactions with algal cell surface hydroxyl groups [39-40]. Hydroxyl groups within GO can also be considered to be Lewis bases, while the more electronegative oxygen groups can be considered as Lewis acids [41]. As such, Lewis acid-base interactions between GO and algae cells can occur. These interactions together with the abovementioned hydrogen bonding can overcome the charge repulsion, thereby enabling GO-mediated sweeping of algae cells.

These results clearly demonstrate that diatomite addition results in the formation of denser floc that can more readily undergo settling. Wu et al. [38] assessed how polymeric aluminum chloride (PAC) and/or diatomite addition was able to influence algae removal, revealing that diatomite addition either with or prior to PAC altered this removal efficiency. In the present study, the sequence of diatomite and GO addition did not impact the resultant algae removal (data not shown). In the previous study, PAC-mediated flocculation occurred primarily via electrostatic neutralization, with diatomite addition following PAC leading to a significant reduction in the zeta potential and more substantial higher charge repulsion between PAC and algae, thus reducing the efficiency of algae removal [38]. In contrast, electrostatic neutralization is not

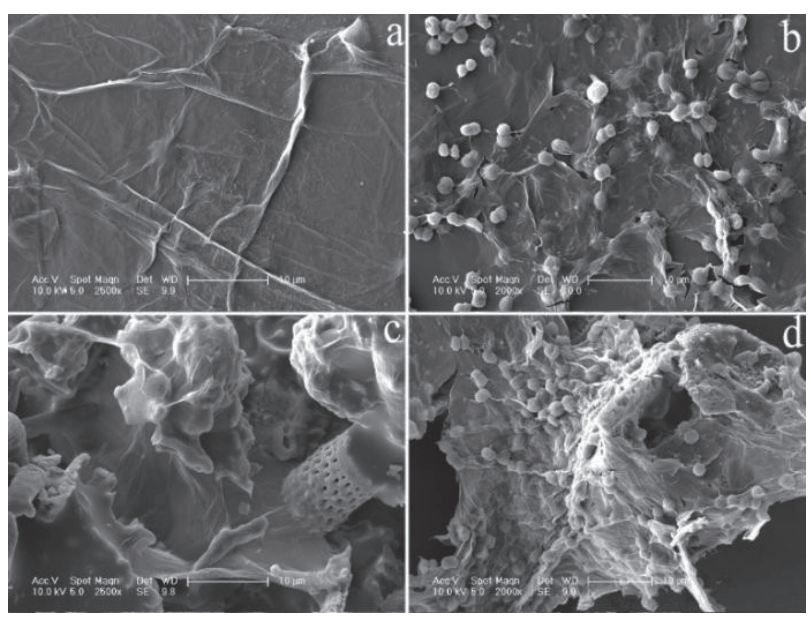

Fig. 6. SEM images of GO a), algae removal by GO flocculation b), $\mathrm{GO} /$ diatomite c) and algae removal by $\mathrm{GO} /$ diatomite flocculation d). a significant contributor to GO-mediated algae removal, and as such, the sequence of diatomite addition did not have any apparent effect on algae removal efficiency.

\section{The Impact of $\mathrm{pH}$ on Flocculation}

The $\mathrm{pH}$ of a given solution can have a strong impact on the flocculation efficiency of any compounds added thereto. To that end, GO-mediated algal flocculation was assessed across a range of $\mathrm{pH}$ levels between 4 and 10. (from 4 to 10). At acidic and neutral $\mathrm{pH}$ values, no significant changes in algal flocculation efficiency were observed (Fig. 7). However, this efficiency declined rapidly as $\mathrm{pH}$ values rose when the $\mathrm{pH}$ was $\geq 7$. At a $\mathrm{pH}$ of $\leq 7$, almost all chl- $a$ and $>97.4 \%$ of the $\mathrm{UV}_{254}$ were removed following flocculation, whereas at a $\mathrm{pH}$ of 10 these values were reduced to $13.8 \%$ and $30.8 \%$, respectively.

As discussed previously, both hydrogen-bonding and Lewis acid-base interactions allow for GO-mediated algae sweeping via overcoming charge repulsion. However, increasing $\mathrm{pH}$ values resulted in reductions in the zeta potential of algae and GO (Fig. 5), leading to charge repulsion. As the $\mathrm{pH}$ continues to rise it becomes more difficult to overcome such charge repulsion, resulting in significantly reduced removal efficiency. In addition, GO surface hydroxyl groups can react with hydroxyl radicals in alkaline solutions, leading to reductions in hydroxyl group availability for hydrogen bonding. Furthermore, in alkaline solutions GO can become deoxygenated into graphene at relatively low temperature [42-43], with these rates of deoxygenation rising with $\mathrm{pH}$ values. Graphene is a hydrophobic compound incapable of bridging or sweeping algal cells, thus leading to the observed marked reductions in flocculation efficiency with rising $\mathrm{pH}$.

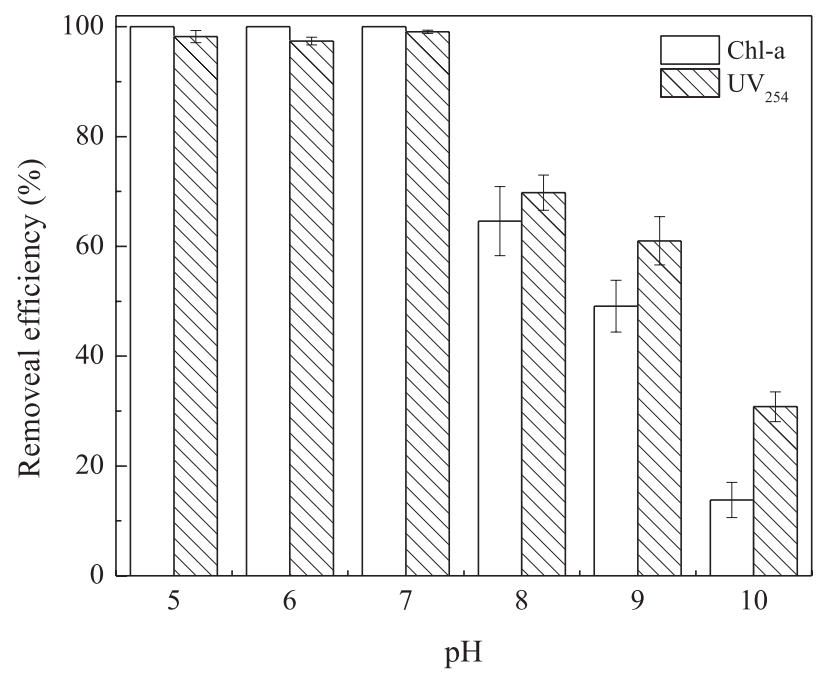

Fig. 7. The impact of $\mathrm{pH}$ on $\mathrm{GO} /$ diatomite flocculation-mediated algae removal. 


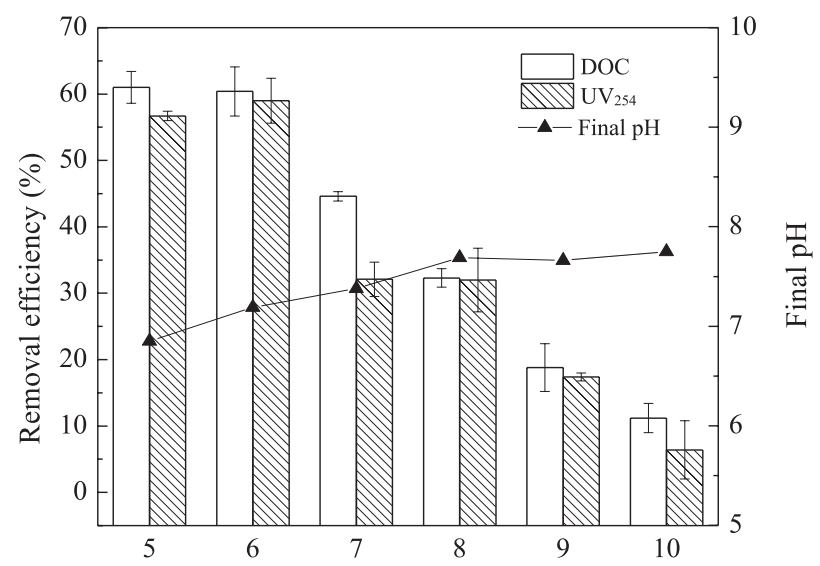

Fig. 8. The impact of $\mathrm{pH}$ on $\mathrm{GO} /$ diatomite flocculation-mediated EOM removal.

\section{GO/Diatomite Flocculation Mediated EOM Removal}

Algal cells are capable of excreting metabolites during both exponential and stationary phases of growth, leading to EOM accumulation that can drive carbonaceous or nitrogenous disinfection by-product formation during disinfection, and which is not readily removed via flocculation or pre-oxidation-enhanced flocculation [14]. Given the excellence of GO/diatomite flocculation of algal cells, we are therefore next assessed the ability of this solution to remove EOM from treated solutions.

EOM flocculation efficiency was significantly affected by $\mathrm{pH}$, declining as $\mathrm{pH}$ values rose (Fig. 8). At a pH of 5, more than $60 \%$ of EOM and $\mathrm{UV}_{254}$ were removed from solution, whereas at a $\mathrm{pH}$ of 10 this removal efficiency was reduced to less than $10 \%$. Interestingly, following GO-mediated flocculation, solution $\mathrm{pH}$ was always $7.4 \pm 0.4$, irrespective of initial

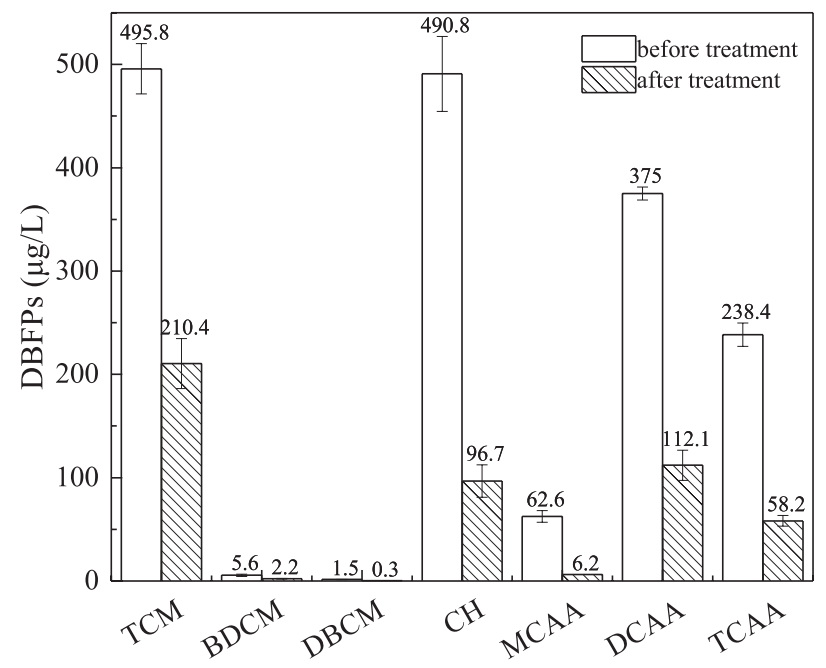

Fig. 9. The impact of GO/diatomite flocculation on disinfection byproduct formation potential.
pH. This is likely because, under acidic conditions, strong negative GO surface charges are able to adsorb hydrogen ions, thereby leading to an increase in $\mathrm{pH}$, whereas under alkaline conditions acid-base neutralization can occur between hydroxyl radicals and GO surface oxygen-containing groups, thereby reducing concentrations of hydroxyl radicals and reducing the $\mathrm{pH}$ of the solution accordingly.

EOM is also an important disinfection byproduct precursor, and the disinfection byproduct formation potentials (DBFPs) was always used to evaluate the precursor of disinfection byproduct removal efficiency. As shown in Fig. 9, the GO/diatomite flocculation could effectively remove the DBPs precursors of EOM, the removal efficiency ranged from $57.6 \%$ to $90.1 \%$. which means the $\mathrm{GO} /$ diatomite flocculation process can effectively decrease the disinfection byproducts formation duding the following disinfection process.

\section{Conclusions}

In conclusion, the results of this study clearly demonstrate that GO can be effectively utilized as a flocculant in order to remove algae from water samples. A $40 \mathrm{mg} / \mathrm{L} \mathrm{GO}$ concentration was sufficient to completely remove $c h l-a$ from solution via netting and bridging flocculation mechanisms. The floc generated by this process, however, was not very dense, and as a result, the supernatant ratio following a $30 \mathrm{~min}$ settling period remained at only $65 \%$. While the addition of diatomite did not directly impact algae removal from water samples, it did result in the conversion of a subset of GO nets from two- to threedimensional structures containing a diatomite core. This in turn significantly enhanced the ability of these samples to settle, with a markedly enhanced (90\%) supernatant ratio after just 8 minutes of settling. Under neutral or acidic conditions, the efficiency of $\mathrm{GO}$ as an algal/EOM flocculant was not significantly affected, although it fell rapidly with rising $\mathrm{pH}$ when $\mathrm{pH} \geq 7$. Following $\mathrm{GO}$ flocculation, the solution always maintained a $\mathrm{pH}$ of $7.4 \pm 0.4$, regardless of the initial $\mathrm{pH}$ value. $57.6 \%$ to $90.1 \%$ of the disinfection byproduct formation potentials can be reduced by $\mathrm{GO} /$ diatomite flocculation process.

\section{Acknowledgements}

The authors wish to thank the Natural Science Foundation of China (NO. 51308252) and Beijing Advanced Innovation Center for Future Urban Design (No. UDC2017032212) for financial support. We also thank Zhongmou Liu, Huan Zhou for supporting us in the experiments. 


\section{Conflict of Interest}

The authors declare no conflict of interest. The founding sponsors had no role in the design of the study; in the collection, analyses, or interpretation of data; in the writing of the manuscript, and in the decision to publish the results.

\section{References}

1. KONG X., HE Q., YANG B., HE W., XU F., JANSSEN A.B., KUIPER J.J., VAN GERVEN L.P., QIN N., JIANG Y. Hydrological regulation drives regime shifts: evidence from paleolimnology and ecosystem modeling of a large shallow Chinese lake. Global Change Biology, 23 (2), 737, 2017.

2. MITSCH W.J. Restoring the Florida Everglades: Comments on the current reservoir plan for solving harmful algal blooms and restoring the Florida Everglades. Ecological Engineering, 138, 155, 2019.

3. QIN B., ZHU G., GAO G., ZHANG Y., WEI L., PAERL H.W., CARMICHAEL W.W. A Drinking Water Crisis in Lake Taihu, China: Linkage to Climatic Variability and Lake Management. Environmental Management, 45 (1), 105, 2010.

4. ULRICH A.E., MALLEY D.F., WATTS P.D. Lake Winnipeg Basin: Advocacy, challenges and progress for sustainable phosphorus and eutrophication control. Science of the Total Environment, 542 (Pt B), 1030, 2015.

5. WATSON S.B., MILLER C., ARHONDITSIS G., BOYER G.L., CARMICHAEL W., CHARLTON M.N., CONFESOR R., DEPEW D.C., HÖÖK T.O., LUDSIN S.A. The re-eutrophication of Lake Erie: Harmful algal blooms and hypoxia. Harmful Algae, 56, 44, 2016.

6. CODD G.A. Cyanobacterial toxins, the perception of water quality, and the prioritisation of eutrophication control. Ecological engineering, 16 (1), 51, 2003.

7. DITTMANN E., WIEGAND C. Cyanobacterial toxinsoccurrence, biosynthesis and impact on human affairs. Molecular nutrition \& food research, 50 (1), 7, 2006.

8. LI L., GAO N., DENG Y., YAO J., ZHANG K. Characterization of intracellular \&amp; extracellular algae organic matters (AOM) of Microcystic aeruginosa and formation of AOM-associated disinfection byproducts and odor \&amp; taste compounds. Water research, 46 (4), 1233, 2012.

9. QUIBLIER C., WOOD S., ECHENIQUE-SUBIABRE I., HEATH M., VILLENEUVE A., HUMBERT J.F.O. A review of current knowledge on toxic benthic freshwater cyanobacteria--ecology, toxin production and risk management. Water Research, 47 (15), 5464, 2013.

10. CHENG W.P., CHI F.H. Influence of eutrophication on the coagulation efficiency in reservoir water. Chemosphere, $\mathbf{5 3}$ (7), 773, 2003

11. HENDERSON R.K., BAKER A., PARSONS S.A., JEFFERSON B. Characterisation of algogenic organic matter extracted from cyanobacteria, green algae and diatoms. Water Research, 42 (13), 3435, 2008.

12. SHEN Q., ZHU J., CHENG L., ZHANG J., ZHEN Z., XU $X$. Enhanced algae removal by drinking water treatment of chlorination coupled with coagulation. Desalination, 271 (1-3), 236, 2011.
13. JEN-JENG C., HSUAN-HSIEN Y. The mechanisms of potassium permanganate on algae removal. Water Research, 39 (18), 4420, 2005.

14. ZHOU J., ZHAO Z., LIU J., PENG W., PENG X., HAN Y., XIAO P. Removal of Microcystis aeruginosa and control of algal organic matters by potassium ferrate(VI) pre-oxidation enhanced $\mathrm{Fe}(\mathrm{II})$ coagulation. Korean Journal of Chemical Engineering, 36 (10), 1587, 2019.

15. DUAN X., SANAN T., DE LA CRUZ A., HE X., KONG M., DIONYSIOU D.D. Susceptibility of the Algal Toxin Microcystin-LR to UV/Chlorine Process: Comparison with Chlorination. Environmental Science \& Technology, 52 (15), 8252, 2018.

16. WOO H., YANG H.S., TIMMES T.C., HAN C., NAM J.Y., BYUN S., KIM S., RYU H., KIM H.C. Treatment of reverse osmosis concentrate using an algal-based MBR combined with ozone pretreatment. Water Research, 159, 164, 2019 .

17. SHAH N.S., ALI KHAN J., SAYED M., UL HAQ KHAN Z., AJID ALI H., MURTAZA, B., KHAN H.M., IMRAN M., MUHAMMAD N., Hydroxyl and sulfate radical mediated degradation of ciprofloxacin using nano zerovalent manganese catalyzed $\mathrm{S}_{2} \mathrm{O}_{8}{ }^{2-}$. Chemical Engineering Journal, 356, 199, 2019.

18. LOGANATHAN K. Ozone-based advanced oxidation processes for the removal of harmful algal bloom (HAB) toxins: a review. Desalination and Water Treatment, 59, 65, 2017.

19. SIMATE G.S., IYUKE S.E., NDLOVU S., HEYDENRYCH M. The heterogeneous coagulation and flocculation of brewery wastewater using carbon nanotubes. Water Research, 46, 1185, 2012.

20. JIAHUA Z., SUYING W., HONGBO G., RAPOLE S.B., QIANG W., ZHIPING L., NEEL H., YOUNG D.P., ZHANHU G. One-pot synthesis of magnetic graphene nanocomposites decorated with core@double-shell nanoparticles for fast chromium removal. Environmental Science \& Technology, 46 (2), 977, 2012.

21. WEI G. The Chemistry of Graphene Oxide. Chemical Society Reviews, 39 (1), 228, 2009.

22. WANG X., LIU Z., YING Z., HUO M., YANG W. Adsorption of Trace Estrogens in Ultrapure and Wastewater Treatment Plant Effluent by Magnetic Graphene Oxide. International Journal of Environmental Research and Public Health, 15 (7), 2018.

23. CHEN D., FENG H., LI J. Graphene oxide: Preparation, functionalization, and electrochemical applications. Chemical Reviews, 112 (11), 6027, 2012.

24. YANG Z., YAN H., YANG H., LI H., LI A., CHENG R. Flocculation performance and mechanism of graphene oxide for removal of various contaminants from water. Water Research, 47 (9), 3037, 2013.

25. ABOUBARAKA A.E., ABOELFETOH E.F., EBEID E.Z.M. Coagulation effectiveness of graphene oxide for the removal of turbidity from raw surface water. Chemosphere, 181, 738, 2019.

26. KHRAISHEH M.A.M., AL-DEGS Y.S., MCMINN W.A.M. Remediation of wastewater containing heavy metals using raw and modified diatomite. Chemical Engineering Journal, 99 (2), 177, 2004.

27. YANG X.L., SONG H.L., LU J.L., FU D.F., CHENG B. Influence of diatomite addition on membrane fouling and performance in a submerged membrane bioreactor. Bioresource technology, 101 (23), 9178, 2010. 
28. HE H., LUO Y., LUO Z., YU C. Diatomite-Based Material as an Adsorbent or Photocatalyst for Water Treatment. Progress in Chemistry, 31 (4), 561, 2019.

29. LYNGSIE G., KATIKA K., FABRICIUS I.L., HANSEN H.C.B., BORGGAARD O.K. Phosphate removal by iron oxide-coated diatomite: Laboratory test of a new method for cleaning drainage water. Chemosphere, 222, 884, 2019.

30. YITBAREK M., ABDETA K., BEYENE A., ASTATKIE H., DADI D., DESALEW G. VAN DER BRUGGEN B. Experimental evaluation of sorptive removal of fluoride from drinking water using natural and brewery waste diatomite. Process Safety and Environmental Protection, 128, 95, 2019.

31. ZHAO Y., TIAN G., DUAN X., LIANG X., MENG J., LIANG J. Environmental Applications of Diatomite Minerals in Removing Heavy Metals from Water. Industrial \& Engineering Chemistry Research, 58 (27), 11638, 2019.

32. BAO C., SONG L., XING W., YUAN B., WILKIE C.A., HUANG J., GUO Y., HU Y. Preparation of graphene by pressurized oxidation and multiplex reduction and its polymer nanocomposites by masterbatch-based melt blending. Journal of Materials Chemistry, 22 (13), 6088, 2012.

33. GAO S., YANG J., TIAN J., MA F., TU G., DU M. Electrocoagulation-flotation process for algae removal. Journal of hazardous materials, 177 (1-3), 336, 2010.

34. YANG, W., DONG, L., LUO, Z., CUI, X., LIU, J., LIU, Z., HUO, M. Application of ultrasound and quartz sand for the removal of disinfection byproducts from drinking water. Chemosphere, 101, 34, 2014.

35. MARCANO D.C., KOSYNKIN D.V., BERLIN J.M., SINITSKII A., SUN Z., SLESAREV A., ALEMANY L. B., LU W., TOUR J.M. Improved synthesis of graphene oxide. ACS nano, 4 (8), 4806, 2010.

36. RAMESHA G.K., VIJAYA KUMARA A., MURALIDHARA H.B., SAMPATH S. Graphene and graphene oxide as effective adsorbents toward anionic and cationic dyes. Journal of Colloid and Interface Science, 361 (1), $270,2017$.

37. ZHAO G., LI J., REN X., CHEN C., WANG X. Fewlayered graphene oxide nanosheets as superior sorbents for heavy metal ion pollution management. Environmental Science and Technology, 45 (24), 10454, 2011.

38. WU C.D., XU X.J., LIANG J.L., WANG Q., DONG Q., LIANG W.L. Enhanced coagulation for treating slightly polluted algae-containing surface water combining polyaluminum chloride (PAC) with diatomite. Desalination, 279 (1-3), 140, 2011.

39. CHEN L.Q., HU P.P., ZHANG L., HUANG S.Z., LUO L.F., HUANG C.Z. Toxicity of graphene oxide and multi-walled carbon nanotubes against human cells and zebrafish. Science China Chemistry, 55 (10), 2209, 2012.

40. HARTONO T., WANG S., MA Q., ZHU Z. Layer structured graphite oxide as a novel adsorbent for humic acid removal from aqueous solution. Journal of Colloid and Interface Science, 333 (1), 114, 2009.

41. GONÇALVES M., SÁNCHEZ-GARCÍA L., OLIVEIRA JARDIM E.D., SILVESTRE-ALBERO J., RODRÍGUEZREINOSO F. Ammonia removal using activated carbons: Effect of the surface chemistry in dry and moist conditions. Environmental Science and Technology, 45 (24), 10605, 2011.

42. FAN X., PENG W., LI Y., LI X., WANG S., ZHANG G., ZHANG F. Deoxygenation of exfoliated graphite oxide under alkaline conditions: a green route to graphene preparation. Advanced Materials, 20 (23), 4490, 2008.

43. JIN Y., HUANG S., ZHANG M., JIA M., HU D. A green and efficient method to produce graphene for electrochemical capacitors from graphene oxide using sodium carbonate as a reducing agent. Applied Surface Science, 268, 541, 2013.

44. LY. Q V., MAQBOOL T., JIN H. Unique characteristics of algal dissolved organic matter and their association with membrane fouling behavior: a review. Environmental Science \& Pollution Research, 24 (12), 11192, 2017. 